\title{
Use of force and International law: Opinions of the Spanish International Legal Office (2004-20I2)
}

\author{
Concepción ESCOBAR HERNÁNDEZ*
}

I. The issue of the use of force in international relations falls squarely within the context of the mandate of the Asesoría Jurídica Internacional (Spanish International Legal Office, hereinafter AJI) as the advisory body of the General State Administration on the subject of international law. In this regard, the AJI clearly cannot ignore the central role of the principle prohibiting the use or threat of use of force in contemporary international law in the ordinary course of its duties. And yet it has rarely been consulted on this issue, except in exceptional circumstances in which the state's external action has been faced with situations that could lead to the participation of Spanish troops in military operations outside Spanish territory that might ultimately involve the use of force. This circumstance, quite infrequent in the past, has gradually taken on greater importance and prominence in Spanish political life, especially following the country's participation in the coalition that invaded Iraq in 2003, prompting strong social mobilization and intense political and academic debate on the legality of the intervention, as well as on the legal and political consequences for Spain of its involvement in the coalition. Unsurprisingly, since then, the AJI has been asked multiple times to issue opinions on the use of force, both directly and indirectly, but always in connection with the actual or potential presence of Spanish troops abroad.

In the period spanning from June 2004 to April 20I2, in which I had the honour of heading the AJI, the office issued quite a few reports on matters of military interest ${ }^{\mathrm{I}}$ or that might affect the interests of Spanish troops participating in peacekeeping operations. ${ }^{2}$ Although all of these matters could be indirectly linked to issues related to the use of force and the application of international humanitarian law, in none of them were such questions actually raised, directly or indirectly. However, on three particular occasions, the AJI was asked to offer an opinion on an

Professor of Public International Law, UNED. Member of the International Law Commission. Former head of the Spanish International Legal Office (2004-2012).

I The AJI issued quite a large number of reports over the period on matters related to defence cooperation, and it is impossible to address them all separately here. Suffice it to cite a few examples that affected particularly significant interests for the country and in which the AJI was actively involved, such as the negotiations with the United Nations for the creation of the UN Communications Centre in Quart de Poblet; the agreements to permanently base US destroyers at Rota, including the early documents that ultimately culminated in the Second Protocol of Amendment to the Hispano-American Agreement on Defence Cooperation; or the AJI's contribution to establishing certain criteria with regard to Operation Atalanta to fight piracy, in which Spain has participated from the start.

For example, with regard to the passage of Spanish Royal Decree-Law 8/2004, of 5 November, on compensation for participants in international peace and security operations (Spanish Official Gazette (BOE) no. 271, Io November 2004). 
issue directly related to the use of force by Spanish troops abroad, namely: i) the death of ten Spanish soldiers in Iraq following the country's invasion by the US-led coalition and in the context of the international presence subsequently established there; ii) the passage of the Spanish Law on National Defence; and iii) the adoption of various enforcement measures in the context of the Libyan conflict and the bombing of civilians in that country in 2orr. Although each of these situations corresponded to a very different reality, in all three cases the AJI offered its opinion on issues directly related to the use of force, namely: i) the rules of international humanitarian law applicable in an armed conflict and in a situation of occupation; ii) the scope of the principle prohibiting the use or threat of use of force, as well as the exceptions thereto; and iii) the powers of the UN Security Council and other international organizations with regard to the use of force. This brief overview does not include the AJI's contributions in relation to the crime of aggression under the Rome Statute of the International Criminal Court, or its contributions to the process of defining, in the context of the EU, a set of principles with regard to the difference and relationship between international humanitarian law and the fight against terrorism. Although both involve elements linked to the use of force and international humanitarian law, each would merit an extensive treatment of its own, which falls beyond the scope of this paper.

The following pages will examine each of the aforementioned cases, in chronological order, placing special emphasis on the main aspects of the AJI's opinions that are relevant to this Agora.

2. In the first of the aforementioned cases, the AJI's opinion was provided in connection with the death of ten Spanish soldiers and civil guards integrated in the international contingent deployed in Iraq following the invasion of that country by an international coalition that included Spain. Although the AJI's opinion was issued subsequent to the withdrawal of the Spanish troops from Iraqi territory, its content necessarily referred to certain events that had taken place when Spain still maintained a presence there. On this occasion, the query submitted to the AJI was not about the legality of that presence or the limits of the use of force by Spanish troops in that conflict, ${ }^{3}$ but rather about possible criminal proceedings in Iraq against people accused of killing ten Spanish soldiers stationed in the country within the context of the occupation.

Although the AJI refrained from making any pronouncement on the criminal proceedings, it issued its opinion on various issues that are relevant to the subject of this Agora, namely: the nature of the presence of foreign troops, including Spain's, in the territory in question and the law applicable to that presence; the nature of the events that caused the deaths of the Spanish soldiers; the status of said soldiers under international law; and the status of the parties

\footnotetext{
The AJI had already issued an opinion on that point prior to the invasion of Iraq. For more information, see the contribution by Ambassador Yáñez-Barnuevo in this Agora.
} 
responsible for the events that caused their deaths under international law. The main elements of that opinion can be summarized as follows:

(i) The international presence following the invasion of Iraq must be considered an occupation. Based on this classification, established by the UN Security Council and acknowledged by the Coalition itself, it is possible to determine the rules applicable to the international presence in Iraq, which are none other than the rules of international humanitarian law applicable to an occupation, especially the Geneva Convention relative to the Protection of Civilian Persons in Time of War, of I2 August 1949, and the first Protocol Additional to the Geneva Conventions (Protocol I), of 8 June 1977, relating to the protection of victims of international armed conflicts, both of which have been ratified by Spain. ${ }^{4}$

(ii) The events leading to the deaths of the Spanish soldiers were of different legal natures, and it is necessary to distinguish between the attack on the UN offices in Baghdad that caused the death of one Spanish soldier and the other acts, which took place within the context of the performance of the inherent functions of the soldiers stationed in the country. Specifically, whilst the former must necessarily be classified as an attack against civilians and internationally protected persons, the latter took place in a military environment and can thus be understood in the context of armed clashes involving lawful combatants.

(iii) The international legal status applicable to individual Spanish troops stationed in Iraq also corresponds to more than one model, as distinctions must be drawn based on the activities in which they engaged within the context of the international presence, namely: (a) participation in Spain's representation before the Coalition Provisional Authority for Iraq; (b) integration in operational military units; and (c) intelligence services. Only in the first case would the Spanish soldier unequivocally fall within the category of "civilian population" and thus be covered by the regime intended to protect it. In the remaining cases, the Spanish soldiers integrated in military units were, as a rule, performing the functions of lawful combatants and, thus, covered by the corresponding legal regime, including the special protection afforded to them under the applicable rules of international humanitarian law. This would moreover include, where appropriate, Article 46 of Protocol I, on the legal system applicable to "spies".

(iv) The perpetrators of the events that caused the deaths of the Spanish soldiers could likewise be subject to different international legal regimes. Thus, whilst the perpetrators of the attack on the UN offices in Baghdad could not under any circumstances be classified as lawful combatants, but rather as the perpetrators of a terrorist act, the same classification could not be automatically applied to the perpetrators of the other acts that resulted in the deaths of Spanish soldiers. Therefore, the classification of the parties responsible for those deaths as "combatants" as per the Geneva Conventions could not be ruled out, provided they met the

4 Convention IV was ratified in an instrument of ratification deposited on 4 August 1952 (BOE no. 246, 2 September 1952), and Protocol I, in an instrument of ratification deposited on 21 April 1989 (BOE no. 177, 26 July 1989). 
requirements established under the Conventions to that end, especially: that they be part of a hierarchical armed structure, that they use recognizable identification, and that they carry their weapons openly. This classification would even be possible in the case of the occasional attacks inherent to so-called "guerrilla warfare" covered under Article 44.3 of Protocol I, which, although it is not generally recognized by Spain, is recognized in relation to occupations. In accordance with that provision, any person who, despite not meeting the aforementioned requirements, carries his arms openly "during each military engagement" and "during such time as he is visible to the adversary while he is engaged in a military deployment preceding the launching of an attack in which he is to participate" shall retain his status as a combatant.

(v) Therefore, the legal effects resulting from each of the acts in question will differ, depending on the legal statuses of the deceased and of the parties responsible for their deaths. Only in the first case can the acts in question be classified as terrorist acts and criminally prosecuted as such. In contrast, in the event of acts of combat, criminal proceedings cannot be instigated against a legitimate combatant who causes the death of an opposing combatant, as long as the acts of combat are carried out in accordance with the rules of international law governing the conduct of hostilities.

In short, although in this case the AJI refrained from offering an opinion on the use of force in abstract terms, and it likewise refrained from legally classifying each of the events resulting in the deaths of the Spanish soldiers in Iraq, its opinion is worth highlighting in this Agora for several reasons. First, it underscores the complexity of the situations that can occur in the context of an armed conflict or an occupation, which precludes a simplistic classification of the acts committed in those situations as legal or not. Second, it calls attention to the possible confluence of multiple legal regimes in a single situation of armed conflict or occupation. Finally, third, it highlights the different international-law statutes to which Spanish troops participating in international missions might be subject, making it impossible to automatically apply the same legal regime to all the soldiers involved in them.

3. The second example has a broader scope, as it refers to the abstract problem of the use of force within the context of the passage of Organic Law 5/2005, 17 November 2005, on National Defence. 5 This occasion was especially important, as the Law on National Defence was the first legal instrument to dictate the types of actions the Spanish army can carry out outside of Spanish territory, the need for the government to obtain parliamentary authorization to deploy Spanish troops abroad, and the conditions to be met for this authorization to be granted. The establishment of these conditions and of the requirement for the government to obtain parliamentary authorization was moreover influenced by the debate that followed Spain's participation in the Coalition that intervened militarily in Iraq, which significantly increased

See BOE no. 276, I8 November 2005. 
political sensitivity to the establishment of the aforementioned rules. In this context, it was particularly important to establish a set of criteria to ensure that the troops would not engage in the use of force in violation of the requirements of international law, whilst at the same time ensuring the continuity of Spain's international presence in various kinds of military operations, in keeping with the country's practice following the adoption of the 1978 Constitution so that the Spanish army would be able to contribute to the international community's efforts to maintain international peace and security.

In this context, the AJI was consulted throughout the internal process of drafting the law, as well as on its passage through Parliament, offering opinions on both the draft bill and the bill submitted to Parliament and the amendments tabled by various parliamentary groups. Over the course of this process, the AJI consistently stressed the following points: (i) the diversity of the international military operations carried out today and the different legal regimes applicable to each one; (ii) the different powers of international organizations to authorize, establish, coordinate or direct each of these international operations with a military component; and (iii) the Security Council's exclusive power to authorize the use of force by a given operation.

The general possibility that the Spanish Armed Forces might participate in international military operations did not pose any problems, as, in reality, Spain had already been participating in various operations previously established by the UN or by other international organizations to which it belonged, especially the EU and NATO. Organic Law 5/2005 provides for the possibility of continuing to participate in such operations in future through the inclusion, as one of the Armed Forces' missions, of "contribut[ing] militarily to the security and defence of Spain and its allies, within the framework of the international organizations of which Spain is a member, and to the maintenance of peace, stability and humanitarian aid". ${ }^{6}$ The law likewise recognizes the diversity of the military operations in which Spain's Armed Forces can participate, providing that this participation will be carried out through "different types of operations, both within national territory and overseas, that may lead to conflict prevention or deterrence actions, peacekeeping actions, actions in crisis situations and, where necessary, actions in response to an aggression".7 This recognition of the diversity of operations in which the Spanish Armed Forces can participate overseas is further specified and reinforced by the explicit reference to "cooperation on operations for the maintenance of international peace and stability in areas where they are threatened, the rebuilding of security and governance, as well as the rehabilitation of a country, region or specific zone, in accordance with the established treaties and commitments". ${ }^{8}$

However, the debate was somewhat thornier when it came to defining the legal regime applicable to the parliamentary authorization and, in particular, the conditions to be met by what

\footnotetext{
See Article 15.2.

See Article 16, heading.

See Article 16 , paragraph b).
} 
the organic law termed "foreign missions". Thus, with the exception of the consensus on the need to obtain the parliamentary authorization of Congress "to order foreign operations that are not directly related to the defence of Spain or the national interest", 9 the process of developing the Organic Law on National Defence was marked by an intense debate to determine in which cases, when Spain's direct interests were not affected, Congress could authorize the sending abroad of Spanish troops that could, if necessary, make use of force in fulfilment of their mandate and, in particular, to identify those cases in which a decision by an international organization could give cover to such a military intervention. Consequently, it was necessary to answer two different, yet interrelated questions: (i) what international acts would enable the participation of Spanish troops in an international mission; and (ii) what role would the UN Security Council and other international organizations play in the establishment of an international military operation and, in particular, in the authorization or establishment of military operations that would necessarily involve the use of force by the participating national contingents.

The subject was especially important, as it highlighted the controversy over the scope of the mandate of international organizations to establish military operations, as well as the equally important question of the exclusivity of the UN Security Council's power to authorize the use of force as allowed under international law. Nor can it be ignored that, underlying the aforementioned debate was the controversy sparked by the invasion of Iraq over the possibility that a group of states, acting unilaterally or by agreement amongst themselves, but in either case outside the established rules and procedures of international law, could decide on a military intervention in a given foreign territory without the express authorization of the affected state.

The AJI's opinion on these issues can be summarized as follows:

(i) The presence of Spanish troops overseas may be covered by the decision of an international organization of which Spain is a member. However, for that decision to enable the involvement of Spanish troops in international military operations, two requirements must be met: a) the organization must be acting within the framework of its powers, taking only those decisions in each case that fall within the scope of its mandate in accordance with applicable international law; and b) the decision must be "formally adopted" by the organization's competent bodies or institutions, such that the military operation may not be based on any statement of intentions or other declaration by a body of the organization that does not expressly provide for the operation's establishment.

(ii) Notwithstanding the above, the participation of Spanish troops in foreign operations involving or potentially involving the use of force will only be possible in the case of an operation ordered or authorized by the UN Security Council under Chapter VII of the Charter. This operation may be carried out directly by the UN itself, by another international organization, or by an alliance established for this purpose by several states.

9 See Article I7.I. 
However, under no circumstances may Spanish troops participate in a military operation strictly requiring the use of force unless said use of force has been previously "authorized" by the Security Council.

(iii) Spanish troops may not participate in international military operations simply under the cover of mere international "commitments" undertaken by Spain outside the context of the two aforementioned cases.

(iv) Logically, these requirements would not apply should the state in whose territory the international military operation is to be deployed itself expressly request or authorize said presence.

Thus, an attempt was made to preserve the distinct nature of the UN Security Council's powers with regard to the maintenance of international peace and security as opposed to those of other international organizations, in particular, the Security Council's unique role as the sole competent body to make exceptions to the principle prohibiting the use or threat of use of force in a given case. Applying these criteria would enable Spanish troops to participate in peacekeeping or crisis management operations set up independently by an organization of which Spain is a member, especially the EU or NATO, without the need for prior authorization from the Security Council, provided that said participation does not involve the use of force above and beyond the legitimate self-defence of the operation's members. In contrast, should the said organizations or a coalition of states seek to establish a military operation whose mandate includes the general use of force, of both a defensive and offensive nature, the presence of Spanish troops would only be possible with the prior authorization of the Security Council as provided for in a resolution adopted under Chapter VII of the Charter.

This approach was incorporated in the Organic Law on National Defence, as witnessed by Article 19, paragraph b), which provides that "[i]n order for the Armed Forces to undertake foreign missions that are not directly related to the defence of Spain or the national interest", said missions must be "conducted by express request of the government of the state in whose territory they are to be carried out or authorized by resolution of the United Nations Security Council or agreed, where applicable, by international organizations of which Spain is a member, in particular, the European Union or the North Atlantic Treaty Organization (NATO), within the framework of their respective powers." ${ }^{\circ}$

\footnotetext{
ro With regard to this provision, it should be noted that the Parliament rejected various amendments tabled by parliamentary groups seeking to limit the possibility of the intervention of Spanish troops solely to cases in which there existed an express authorization by the Security Council (Grupo Parlamentario Izquierda Verde-Izquierda Unida-Iniciativa per Catalunya/Verts (Green Left-United Left-Initiative for Catalonia/Greens Parliamentary Group); Grupo Parlamentario Mixto-BNG (Mixed-Galician National Block Parliamentary Group); and Grupo Parlamentario Mixto-Eusko-Alkartasuna (Mixed-Basque Solidarity Parliamentary Group)) or in the case of an aggression against the state in whose territory the operation was to be conducted when said aggression had been established by an international organization other than the United Nations (Grupo Parlamentario Esquerra Republicana (Republican Left Parliamentary Group)). It likewise rejected another set of amendments intended to loosen the conditions required for the participation of Spanish forces through the inclusion of generic references to the interests of Spain, to the existence of "other international commitments duly undertaken by Spain within the context of its external action", the content of which was not specified, or to the fact that the
} 
4. The third case in which the AJI had to pronounce itself on the use of force during the period was related to the crisis in Libya. Following the adoption of SC Res. I970 (20II), and as a result of the increase in systematic bombing by General Gaddafi's troops of the civilian population, causing a high number of casualties and a dramatic displacement of the population towards the borders of neighbouring states, there arose the need to adopt effective measures to prevent the bombings, as well as to enforce the arms embargo established by SC Res. 1970 (20II) and to facilitate the provision of humanitarian assistance to the displaced persons and other civilians. In this context, the possibility of establishing a no-fly zone, a naval blockade and a humanitarian relief operation was raised in various forums, especially international organizations, including the EU and NATO.

The AJI was consulted with regard to the compatibility of each of the three proposals with international law and the legal difficulties their implementation might entail. In keeping with the previously formulated approach to the limits of the use of force, the AJI reiterated its opinion that the use of force in Libyan territory or against Libyan troops would only be possible following the adoption of the relevant Security Council resolution under Chapter VII of the UN Charter. The relevant elements of this opinion in the present context can be summarized as follows:

(i) Any action involving the use of armed force in Libya, or the entry of foreign troops in Libya, would require prior authorization from the Security Council.

(ii) The establishment of a no-fly zone requiring any type of action in Libyan airspace, including the overflying thereof, by foreign military aircraft without Libyan consent would constitute a violation of Libya's territorial integrity and, therefore, could only be carried out with the pertinent authorization of the Security Council. The same would be true were the no-fly zone to require the overflight of the airspace of any neighbouring state that had not given its express authorization.

(iii) SC Res. I970 (20II) contains no measures authorizing the use of force to enforce the arms embargo. Therefore, any control mechanism established in the Mediterranean to monitor ships navigating through it in order to prevent them from carrying arms to Libya would be subject to the rules of the law of the sea. In particular, the requirement for the inspection, search, arrest or seizure of the ship in question to be carried out only by the state whose flag the ship was flying or with said state's authorization would need to be met. Exceptions could only be made to this constraint if the Security Council were to adopt another resolution under Chapter VII of the Charter authorizing such measures, including the use of force.

operation was simply "supported" by the UN Security Council or "had the cover, where applicable, of decisions adopted by international organizations of which Spain is a member" (Grupo Parlamentario Popular (People's Party Parliamentary Group)). 
(iv) Humanitarian assistance measures would be limited solely by the prohibition of the use or threat of use of force to ensure their implementation, again unless the Security Council were to adopt a resolution authorizing the use of such force.

The AJI's opinion was confirmed by SC Res. 1973 (2011), of 17 March, which established a no-fly zone over Libyan territory and authorized the taking of all necessary measures to enforce it, ${ }^{\text {II }}$ whilst at the same time ordering all states "to inspect in their territory, including seaports and airports, and on the high seas, vessels and aircraft bound to or from" Libya in order to enforce the arms embargo, authorizing the use of "all measures commensurate to the specific circumstances to carry out such inspections". ${ }^{2}$ Finally, the Security Council adopted a similar decision with regard to the protection of threatened civilians in Libya, including Benghazi, to which end it authorized all states to use "all necessary measures", with the sole exception of the establishment of "a foreign occupation force of any form on any part of Libyan territory". ${ }^{23}$ Thus, the Security Council, by means of the standard formula in its resolutions of authorizing "all necessary means", authorized the use of force to achieve all three of the aforementioned objectives.

5. The three cases briefly discussed above are a good example of how the AJI has interpreted the principle prohibiting the use or threat of use of force in the exercise of its functions as an advisory body of the General State Administration on matters of international law. This interpretation has moreover traditionally been maintained within the framework of an orthodox interpretation consistent with both international practice and international legal doctrine, thereby helping to ensure the respect for international law to which Spain has repeatedly expressed its unequivocal commitment.

II See, especially, operative paragraphs 6 and 8 .

I2 See, especially, operative paragraph $\mathrm{i} 3$.

I3 See, especially, operative paragraph 4. 